Disclosure of Interest: K. Price Employee of: Bristol-Myers Squibb, Y. Doleh Employee of: Bristol-Myers Squibb, M. Eaddy Consultant for: Xcenda, A. Ogbonnaya Employee of: Xcenda, H.-C. Shih Employee of: Xcenda, H. Ahmad Shareholder of: Bristol-Myers Squibb, Employee of: Bristol-Myers Squibb, L. Lamerato Grant/research support from: Centers for Disease Control, National Cancer Institute, Policy Analysis, Inc, Outcomes Research Solutions, Xcenda, eMAXHealth, Merck Pharmaceuticals, Pfizer Pharmaceuticals, Reagan Udall Foundation, AstraZeneca, Employee of: Henry Ford Health System, University of Michigan-Dearborn, A. Szymialis Shareholder of: Bristol-Myers Squibb, Employee of: Bristol-Myers Squibb

DOI: 10.1136/annrheumdis-2017-eular.1794

\section{SAT0189 FACTORS INFLUENCING THE PRESCRIPTION OF TOCILIZUMAB ALONE OR IN COMBINATION WITH DMARDS IN RHEUMATOID ARTHRITIS PATIENTS IN A REAL LIFE SETTING. POOLED ANALYSIS OF 3 OBSERVATIONAL STUDIES}

A. Saraux ${ }^{1}$, A. Cantagrel ${ }^{2}$, B. Combe ${ }^{3}$, R.-M. Flipo ${ }^{4}$, I. Idier ${ }^{5}$, C. Baffie ${ }^{6}$, J. Tebib ${ }^{7} .{ }^{1}$ Rheumatology, University Hospital, Brest; ${ }^{2}$ Rheumatology, University Hospital, Toulouse; ${ }^{3}$ Rheumatology, University Hospital, Montpellier; ${ }^{4}$ Rheumatology, University Hospital, Lille; ${ }^{5}$ Medical, Chugai Pharma France, Paris la Defense; ${ }^{6}$ Statistics, Roche SAS, Boulogne; ${ }^{7}$ Rheumatology, University Hospital, Lyon, France

Background: Tocilizumab (TCZ) as monotherapy (Mono) is nowadays a standard treatment in rheumatoid arthritis (RA) for patients in whom methotrexate (MTX) is inappropriate ${ }^{1}$

Objectives: To describe factors influencing the use of TCZ in Mono or in combination with DMARDs (Combo) in real-life practice in RA patients (pts).

Methods: Analysis: pooled data of 3 prospective, multicentre, observational studies (PEPS $n=610$, Spare- $1 n=307$, Act-solo $n=577$ ). Patients: RA pts requiring TCZ treatment according to their physician. Treatment: TCZ as prescribed in real life. Endpoint: Evaluation of factors influencing the use of TCZ in Mono or in Combo. Data collected: demographic characteristics, past medical history, RA characteristics and history including previous RA treatments, TCZ treatment strategy (Mono or Combo). Statistical analysis: Pts fulfilling inclusion and noninclusion criteria and with $\geq 1 \mathrm{TCZ}$ infusion were analyzed. 1- descriptive analysis 2- Univariate and multivariate analysis to determine factors influencing the use of TCZ in Mono. Variables with more than $20 \%$ of missing data were excluded from the multivariate model.

Results: 1494 pts ( 3 studies) were analysed at inclusion. Pts' characteristics: $56 \%$ of the pts were $>55$ years old, $79.6 \%$ female, mean RA duration $11.1 \pm 9.3$ years, $83.0 \%$ positive for rheumatoid factors and/or ACPA, $77.3 \%$ with erosive disease on X-rays, mean ESR $29.9+23.1 \mathrm{~mm}$, mean CRP $19.9+26.2 \mathrm{mg} / \mathrm{l}$ mean DAS 28-ESR $5.21 \pm 1.22$, mean HAQ-DI $1.56 \pm 0.68$, and mean pain VAS $61.5 \pm 23.2$. Past RA treatment included csDMARDs in $98.5 \%$ and biologics in $77.8 \%$ (median $=2$ [1-6]). TCZ was initiated as Mono in $36.4 \%$ of pts and in Combo in $63.6 \%$, with MTX in $83.3 \%$ of Combo pts (mean dose $15.7 \pm 4.4 \mathrm{mg} / \mathrm{week}$ ). Corticosteroids were used in $74 \%$ of pts (mean dose $10 \pm 7 \mathrm{mg} /$ day). Variables associated with a TCZ prescription in Mono were age ( $\geq 65$ years), number of previous bDMARD, use/dose of steroids, ESR/CRP values, VAS global activity (physician and pt), pain VAS and HAQ-DI. In the multivariate analysis, variables associated with a TCZ prescription in Mono were age $\geq 65$ years $(\mathrm{OR}=1.71$ [1.30 - 2.24], $p<0.001)$, number of previous bDMARD ( 1 bDMARD, OR=1.35 [0.94 - 1.92], 2 bDMARD OR=1.82 [1.28 - 2.60], $\geq 2$ bDMARD, OR=1.19 [0.82 - 1.71] $p=0.006)$, higher pain VAS $(\mathrm{OR}=1.09$ [1.04 - 1.15], $p=0.001)$, higher ESR value ( $O R=1.07$ [1.02 - 1.12], $p=0.013)$.

Conclusions: This pooled analysis suggests that physicians preferably prescribe TCZ alone in older patients, heavily treated before, with higher inflammatory markers and higher pain VAS. This use might be explained by physicians' reluctance to prescribe the association in frailer patients and complementary data on comorbidity factors will be analysed to support this hypothesis.

References:

[1] JS. Smolen et al, Ann Rheum Dis doi:10.1136/annrheumdis-2013-204573. Disclosure of Interest: A. Saraux: None declared, A. Cantagrel: None declared, B. Combe Consultant for: Chugai Pharma France, R.-M. Flipo Consultant for: Chugai Pharma France, I. Idier Employee of: Chugai Pharma France, C. Baffie Employee of: Altizem for Roche SAS, J. Tebib: None declared DOI: 10.1136/annrheumdis-2017-eular.2916

\section{SAT0190 ESTIMATE OF CLINICAL AND ANTIDESTRUCTIVE EFFECTS OF RITUXIMAB IN RHEUMATOID ARTHRITIS}

A.V. Pivanova, G. Lukina, Y. Sigidin, A. Smirnov, K. Kuzikyants, A. Kuznetsova. Nasonova Research Institute of Rheumatology, MOSCOW, RUSSIA, Moscow, Russian Federation

Background: Rheumatoid arthritis (RA) is a chronic inflammatory disease characterized by synovial hyperplasia, mononuclear cell infiltration, bone erosion and joint destruction. Antirheumatic treatment plays a important role in controlling the inflammation of rheumatoid arthritis and in minimizing joint damage. Rituximab - it is a chimeric monoclonal antibody that targets the CD20 molecule expressed on the surface of B cells. It has been successfully used to treat rheumatoid arthritis, and it is worth noting that his antidestructive effect sometimes does not meet the clinical.
Objectives: to assess clinical and antidestructive effect of Rituximab (RTX) in patients with rheumatoid arthritis (RA).

Methods: 108 patients (pts) with RA, most of them were middle-age women with high disease activity (mean DAS28 6,1 11,04 , RF-positive 77\%, ACCP-positive $83 \%$ ) treated with RTX (1000 mgx2 or $500 \mathrm{mgx}$ ). Clinical effect was evaluated by EULAR criteria; radiological progression by SVH method.

Results: 104 patients were treated by RTX $(500 \times 2$ or $1000 \times 2)$, had good response: after 48 week of treatment clinical improvement was achieved in $65 \%$ pts, good and moderate response by EULAR criteria in $23 \%$ and $42 \%$ pts accordingly. Noteworthy, after 12 months of treatment RTX radiological progression was absent in $50 \%$ pts with high disease activity.

Conclusions: RTX treatment slowed joint damage without clinical improvement. Clinical and antidestructive results did not always coincide which suggests different mechanisms of clinical and antidestructive effects of anti-B-cell therapy Disclosure of Interest: None declared

DOI: 10.1136/annrheumdis-2017-eular.6524

\section{SAT0191 PATTERNS OF INTERSTITIAL LUNG DISEASE IN RHEUMATOID ARTHRITIS AND ABATACEPT. MULTICENTER STUDY OF 63 PATIENTS}

C. Fernández-Díaz ${ }^{1}$, S. Castañeda ${ }^{2}$, C. Ojeda $^{3}$, A. Olivé $^{4}$, P. Carreira ${ }^{5}$,

T. Perez-Sandoval ${ }^{6}$, M. Retuerto $^{7}$, E. Cervantes $^{8}$, S. Rodriguez $^{4}$, B. Robles ${ }^{9}$,

B. Hernandez ${ }^{3}$, A. Urruticoechea ${ }^{10}, \mathrm{O}_{\text {Maiz }}{ }^{11}$, D. Palma ${ }^{12}$, L. Arboleya ${ }^{13}$,

G. Bonilla ${ }^{14}$, I. Rodriguez ${ }^{15}$, C. Delgado ${ }^{16}$, R. Exposito ${ }^{17}$, A. Ruibal ${ }^{18}$,

J. Blanco ${ }^{19}, \mathrm{M}^{2}$ Rodriguez ${ }^{20}, \mathrm{~J}$. Bernal ${ }^{21}$, P. Vela ${ }^{21}$, B. Alvarez ${ }^{22}$, C. Fito ${ }^{23}$,

J. Narvaez ${ }^{24}$, M. Moreno ${ }^{25}$, M. Lopez ${ }^{26}$, N. Mena ${ }^{27}$, S. Romero ${ }^{28}$,

C. Aguilera ${ }^{29}$, S. Ordoñez ${ }^{30}$, I. Villa ${ }^{31}$, V. Mora ${ }^{1}$, M. Gonzalez-Gay ${ }^{1}$,

J. Hernandez ${ }^{1}$, R. Blanco $1 .{ }^{1} H U M V$, Santander; ${ }^{2} H$. Princesa, Madrid; ${ }^{3} \mathrm{H}$

Macarena, Sevilla; ${ }^{4} \mathrm{H}$ Trias, Barcelona; ${ }^{5} \mathrm{H} 12$ Octubre, Madrid; ${ }^{6} \mathrm{H} ;{ }^{7} \mathrm{H}$., Leon;

${ }^{8} \mathrm{H}$, Santiago; ${ }^{9} \mathrm{H}$. P Hierro, Madrid; ${ }^{10} \mathrm{H}$, Ibiza; ${ }^{11} \mathrm{H}$, Donostia; ${ }^{12} \mathrm{H}$, Lorca; ${ }^{13} \mathrm{H}$,

Oviedo; ${ }^{14} \mathrm{H}$. Paz, Madrid; ${ }^{15} \mathrm{H}$, Vigo; ${ }^{16} \mathrm{H}$., Zaragoza; ${ }^{17} \mathrm{H}$., Laredo; ${ }^{18} \mathrm{H}$., Araba;

${ }^{19} \mathrm{H}$. Basurto, Bilbao; ${ }^{20} \mathrm{H}$., Ourense; ${ }^{21} \mathrm{H}$., Alicante; ${ }^{22} \mathrm{H}$, Araba; ${ }^{23} \mathrm{H}$, Pamplona;

${ }^{24} \mathrm{H}$. Bellvitge, Barcelona; ${ }^{25} \mathrm{H}$.Arrixaca, Murcia: ${ }^{26} \mathrm{HVHebron}$, Barcelona: ${ }^{27} \mathrm{H}$,

Malaga; ${ }^{28} \mathrm{H}$, Pontevedra; ${ }^{29} \mathrm{H}$, Sevilla; ${ }^{30} \mathrm{H}$, Lleida; ${ }^{31} \mathrm{H}$, Sierrallana, Spain

Background: Disease modifying antirheumatic drugs (DMARDs) such as methotrexate (MTX), leflunomide (LFN) or antiTNF $\alpha$ have been implicated in development/exacerbation of Interstitial lung disease (ILD)of rheumatoid arthritis (RA). Several radiological patterns of ILD have been described: i) usual interstitial pneumonia (UIP), ii) nonspecific interstitial pneumonia (NSIP), iii) obliterating bronchitis (OB), and iv) Organized pneumonia (OP)

Objectives: To assess the response to Abatacept (ABA) in these patterns of ILD Methods: Multicenter study of RA-ILD treated with ABA. ILD was diagnosed by high-resolution CT scan (HRCT) and classified in radiological patterns (Travis et al). We consider 3 subgroups: a) UIP, b) NSIP and c) "other" (OB, OP or mixed). ABA was used at iv or sc standard dose. We assessed: a) Dyspnea (Medical Research Council-modified scale; significant variations $\geq 1$ ); B) Respiratory function tests; significant changes $\geq 10 \%$ in forced vital capacity (FVC) and $\mathrm{DLCO} \leq 10 \%$, c) HRCT, d) DAS28. A comparative study was performed for the quantitative (U-Mann-Whitney) and qualitative variables (Fisher test) between the baseline and 3, 6 and 12 months.

Results: We included 63 patients (27 women/36 men), mean age; $63.1 \pm 9.6$ years. At ABA onset the RA had a median evolution of 6.8 [2-13.6] years and the ILD of 1 [0.3-3.03]. RA was seropositive in $85.7 \%$. The diagnosis of ILD was confirmed by biopsy ( $n=18)$. The ILD was related to DMARDs: MTX (4), etanercept (3), adalimumab (3), certolizumab (2), Infliximab (1). ABA was used in monotherapy (26) or combined with other DMARDs (37); LFN (15), Cyclosporin (1), sulfasalazine (4), MTX (6), hydroxychloroquine (10), azathioprine (4), chloroquine (1). Table 1 shows the evolution in the available cases. A significant improvement in dyspnea and HRCT was observed in the NIU type. DLCO remained stable in most patients regardless of the radiological pattern. The activity of RA (DAS28) also improved.

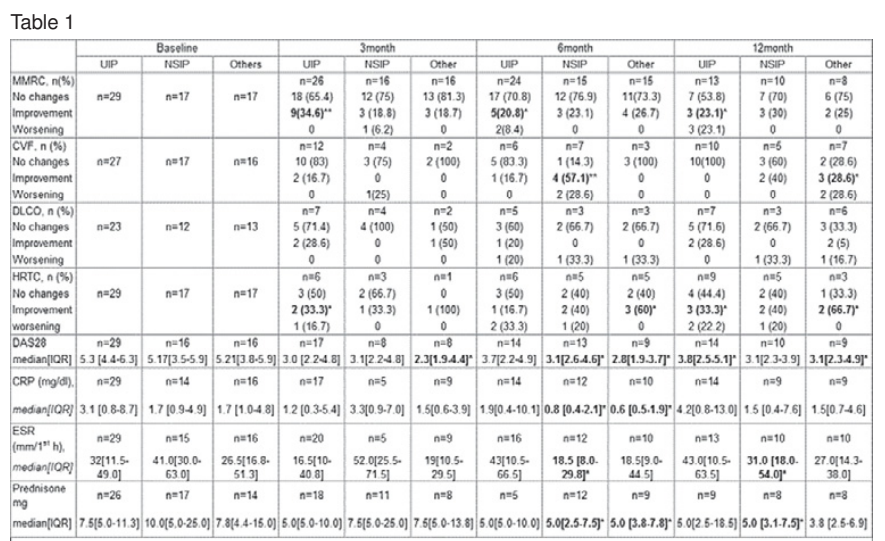

